\title{
APONTAMENTOS E PERCURSOS METODOLÓGICOS NAS PESQUISAS DO ESTADO DA ARTE EM EDUCAÇÃO MATEMÁTICA
}

\section{METHODOLOGICAL NOTES AND PATHWAYS ON STATE OF THE ART RESEARCH IN MATHEMATICS EDUCATION}

\author{
Rodrigo Medeiros dos Santos ${ }^{1}$; Dario Fiorentini ${ }^{2}$
}

\begin{abstract}
RESUMO
Diante da crescente necessidade de organização, sintetização e mapeamento da produção acadêmica em Educação Matemática, aliada à progressiva popularização das pesquisas do tipo estado da arte no Brasil, este artigo busca apresentar e discutir pressupostos e apontamentos teóricos referentes à metodologia da pesquisa na modalidade consagrada sob a denominação de estado da arte. Para tanto, um ensaio teórico é desenvolvido no intuito de destacar as principais etapas, adversidades e especificidades dentro desta modalidade de investigação. São descritos e discutidos em detalhes os procedimentos metodológicos para o garimpo da produção, as bases de dados, a seleção das variáveis e seus tipos, a composição das categorias temáticas e, por fim, a técnica de análise conhecida como Análise de Conteúdo. Os aspectos de caráter prático são destacados, sobretudo no que tange o processo de pré-análise, que inclui as fases de definição dos descritores para direcionar as buscas a serem realizadas; localização dos bancos de pesquisas em bibliotecas digitais e sites de busca; o estabelecimento de critérios para a seleção do material; o efetivo levantamento das pesquisas catalogadas; a leitura sistemática e exploratória dos textos, com elaboração de sínteses preliminares; a organização do relatório de estudo compondo a sistematização das sínteses; e a elaboração das conclusões preliminares. Os principais resultados destacam a complexidade do processo de classificação das variáveis do estudo por meio da técnica de análise de conteúdo; a composição das categorias temáticas, que desponta como um dos maiores desafios nesta modalidade investigativa; e, por fim, a necessidade de produção de novos dados com base nos dados coligidos. Esta produção manifesta-se na medida em que as pesquisas são analisadas e desta análise despontam novos conhecimentos e informações que só são possíveis a partir de inventários dessa natureza.
\end{abstract}

Palavras-chave: Estado da arte; Educação Matemática; Análise de Conteúdo.

\footnotetext{
${ }^{1}$ Doutorado em Educação pela Universidade Estadual de Campinas (UNICAMP). Professor Adjunto na Universidade Federal do Oeste do Pará, Santarém, Pará, Brasil. Endereço para correspondência: Av. Marechal Rondon - de 1894/1895 à 2557/2558, Aparecida, Santarém, Pará, Brasil, CEP: 68040-070. Email: rodrigomedeiros182@hotmail.com

ORCID iD: https://orcid.org/0000-0002-9108-9826.

${ }^{2}$ Doutorado em Educação pela Universidade Estadual de Campinas (UNICAMP). Professor Doutor da Universidade Estadual de Campinas (UNICAMP), Campinas, São Paulo, Brasil. Endereço para correspondência: Barão Geraldo, Campinas, São Paulo - Brasil - Caixa-postal: 6120, CEP: 13083-970. Email: dariofiore@ terra.com.br.
}

D ORCID iD: https://orcid.org/0000-0001-5536-0781. 


\section{ABSTRACT}

In view of the growing need for organizing, synthesizing and mapping academic production in Mathematics Education, coupled with the progressive popularization of state-of-the-art research in Brazil, this article seeks to present and discuss theoretical assumptions and notes regarding the research methodology known as state of the art. Therefore, a theoretical essay is developed in order to highlight the main stages, adversities and specificities within this type of investigation. The methodological procedures for mining the production, the databases, the selection of variables and their types, the composition of the thematic categories and, finally, the analysis technique known as Content Analysis are described and discussed in detail. Practical aspects are highlighted, especially with regard to the pre-analysis process, which includes the definition stages of the descriptors to direct the searches to be carried out; location of research banks in digital libraries and search engines; the establishment of criteria for the selection of the material; the effective survey of cataloged research; systematic and exploratory reading of the texts, with the preparation of preliminary summaries; the organization of the study report composing the synthesis systematization; and the elaboration of preliminary conclusions. The main results highlight the complexity of the process of classifying the study variables using the content analysis technique; the composition of the thematic categories, which emerges as one of the greatest challenges in this investigative modality; and, finally, the need to produce new data based on the collected data. This production manifests itself as research is analyzed and from this analysis emerge new knowledge and information that are only possible from inventories of this nature.

Keywords: State of the art; Mathematics Education; Content Analysis. 


\section{Introdução}

A produção em determinado campo investigativo costuma gerar inevitavelmente um acúmulo desordenado de conhecimento na medida em que novas pesquisas são produzidas e o campo passa a receber incrementos e/ou redefinições. Este acúmulo costuma impedir uma visão global do estado atingido pelo conhecimento e que permita responder questões como: Quais são os temas mais focalizados? Como eles têm sido explorados? Sob que perspectivas teóricas? Quais as principais contribuições dessas publicações para a área? Quais abordagens metodológicas têm sido empregadas? Quais as perspectivas para o cenário futuro neste campo de investigação?

Pesquisas que buscam revelar o conhecimento acerca da totalidade de pesquisas em determinado campo investigativo, na busca de caracterizar e descrever a produção, são conhecidas como estado da arte. Estudos dessa natureza visam, portanto, realizar um balanço em uma determinada área de conhecimento, com a finalidade de diagnosticar temas relevantes, emergentes e recorrentes (ROMANOWSKI; ENS, 2006). Trata-se de "um mapa que nos permite continuar caminhando; uma possibilidade de perceber discursos que em um primeiro exame se apresentam como descontínuos ou contraditórios; uma possibilidade de contribuir com a teoria e a prática" (MESSINA, 1998, p. 23).

Desta forma, o estado da arte emerge como um sistema de análise que busca superar as limitações produzidas na interpretação, avaliação e compreensão do grande volume de conhecimento disperso, fragmentado ou isolado que se observa na produção geral em determinada área do conhecimento. Sua aplicação metodológica visa a ordenação, a organização e a sintetização dos resultados já produzidos num cenário de compreensão que permita avaliar os rumos da pesquisa, suas características intrínsecas e, sobretudo, sua configuração geral.

Essencialmente de caráter bibliográfico, esta modalidade de investigação é comumente apresentada em diversos estudos acadêmicos, geralmente de forma introdutória e sintetizada, embora esse mapeamento também seja tomado em pesquisas como seu foco exclusivo e principal. Para Ferreira (2002), o que move o pesquisador ao intento de realizar um estado da arte é a sensação de não conhecimento acerca da totalidade de estudos e pesquisas em determinada área de conhecimento que apresenta tanto conhecimento qualitativo como quantitativo, principalmente reflexões 
desenvolvidas em nível de pós-graduação, produção esta distribuída por inúmeros programas e pouco divulgada.

Outra característica da pesquisa do estado da arte é a sua infinitude, ponto também notado por Teixeira (2006), segundo o qual pesquisas do estado da arte estão sempre inconclusas e não podem ser finitas, uma vez que há de se observar o movimento ininterrupto da ciência, com os conceitos em constante processo de mutação devido às intervenções do próprio conceito de campo e, consequentemente, dos autores nele inseridos. Assim, pesquisas do estado da arte são sempre passíveis de atualizações e reinterpretações, na medida em que novas pesquisas são publicadas (ou pesquisas antigas são disponibilizadas) e o campo sofre revisões e/ou acréscimos.

Trata-se de uma modalidade de pesquisa usual em vários países e que recentemente vem ganhando notável expressão no cenário brasileiro, onde pesquisas têm sido desenvolvidas nas mais variadas subáreas de investigação dentro do campo da Educação, como, por exemplo, para mapear estudos sobre formação de professores (ANDRÉ, 2002), pesquisas sobre alfabetização (SOARES, 1989), Educação Matemática (FIORENTINI, 1994), ensino de Ciências no ensino Fundamental (MEGID NETO, 1999), pesquisas em leitura (FERREIRA, 1999), dentre outros. Um dos trabalhos pioneiros na discussão da pesquisa educacional brasileira é o de Gouveia (1971), que descreve e analisa a trajetória da pesquisa educacional no país, identificando e caracterizando suas fases históricas e principais tendências temáticas.

A crescente aceitação dessa modalidade de investigação entre os pesquisadores nas diversas áreas, e a sua popularização - na medida em que a produção acadêmica aumenta e acumula-se -, demandam um melhor entendimento a respeito do seus pressupostos metodológicos, assim como o estabelecimento de quadros de referência que indiquem possíveis caminhos, além da superação de certas dificuldades de ordem prática na condução de uma pesquisa do estado da arte.

Com o fim de atingir essa e outras discussões, esta pesquisa busca investigar aspectos ligados aos procedimentos metodológicos envolvidos na elaboração de uma pesquisa do estado da arte, destacando, sobretudo, o processo de composição das categorias temáticas e a técnica de Análise de Conteúdo. 


\section{Alguns breves apontamentos metodológicos}

Segundo os objetivos da investigação, esta pesquisa é caracterizada como um ensaio teórico, porque busca (re) construir ou desenvolver "teorias, conceitos, ideias, ideologias, polêmicas, tendo em vista, em termos imediatos, aprimorar fundamentos teóricos" (DEMO, 2000, p. 20 apud FIORENTINI; LORENZATO, 2009, p. 69).

São discutidas as principais etapas, adversidades e especificidades metodológicas dentro do quadro de elaboração de uma pesquisa do estado da arte, com a construção de quadros de referência que possam nortear a teoria e a prática dentro dessa modalidade investigativa.

\section{A pesquisa do estado da arte e seus pressupostos metodológicos}

De uma maneira geral, são definidos os seguintes procedimentos norteadores para a elaboração de uma pesquisa do estado da $\operatorname{arte}^{3}$ (SANTOS, 2015; ROMANOWSKI, 2002; FREITAS; PALANCH, 2015):

- Definição dos descritores para direcionar as buscas a serem realizadas;

- Localização dos bancos de pesquisas em bibliotecas digitais e sites de busca que possam proporcionar acesso aos textos, resumos ou dados bibliográficos;

- Estabelecimento de critérios para a seleção do material que compõe o corpus do estado da arte;

- Levantamento das pesquisas catalogadas;

- Leitura dos trabalhos com elaboração de síntese preliminar, considerando o tema, os objetivos, problemáticas, metodologias, principais conclusões/resultados e outras variáveis de interesse;

- Organização do relatório de estudo compondo a sistematização das sínteses, identificando as tendências dos temas abordados e as relações indicadas nas pesquisas;

- Análise e elaboração das conclusões preliminares.

Uma vez definido o campo investigativo no qual o pesquisador pretende desenvolver o estado da arte, parte-se para a definição do tipo de pesquisa que comporá o corpus de análise do estudo, podendo ser contempladas teses, dissertações, artigos

3 A enumeração desses procedimentos gerais não delimita e tampouco esgota as possibilidades metodológicas de realização de pesquisas dessa natureza. A prescrição do desenho metodológico apresentado serve apenas como parâmetro norteador, uma vez que cada investigação guarda particularidades moldadas em seus objetivos intrínsecos. 
publicados em periódicos, jornais, revistas, anais de eventos etc. De uma maneira geral, teses e dissertações costumam ser a escolha mais comum. Em primeiro lugar, pela maior consistência teórico-metodológica dos trabalhos produzidos no âmbito dos cursos de pósgraduação stricto-sensu, uma vez que são geralmente constituídos a partir de rigorosa orientação e posteriormente julgados e aprovados por uma banca examinadora; em segundo lugar, pelo fato de que pesquisas produzidas fora do âmbito de pós-graduação, além de possuírem relatos mais sintéticos e objetivos que aqueles expressos em dissertações ou teses acadêmicas, raramente explicitam o processo de investigação, dificultando a análise de inquérito das mesmas; e, por último, o fato de que, devido a sua maior abrangência, consistência e profundidade teóricas, teses e dissertações geralmente conseguem congregar com êxito a pesquisa dispersa em múltiplas plataformas (artigos, resumos, anais, livros, etc.).

Outra definição importante no desenho metodológico da pesquisa é a abrangência do levantamento. Os estudos do tipo estado da arte podem abranger a produção em um determinado curso, programa, instituição ou área específica do conhecimento. Também podem ser delimitados por país, região, estado ou período. Naturalmente, para o pesquisador que busca investigar a gênese da pesquisa em determinado país, estado, região ou programa, convém não adotar um limite inferior para o período investigado. Outra delimitação possível é analisar trabalhos apresentados em um determinado evento acadêmico (neste caso, o material de análise geralmente é composto pelas pesquisas publicadas nos anais do evento).

Nos últimos anos, a composição do corpus de análise em pesquisas do estado da arte tem ocorrido preponderantemente em catálogos disponibilizados na forma de acervos digitais da internet (catálogos de faculdades, institutos, universidades, associações nacionais e órgãos de fomento da pesquisa). Estes catálogos, segundo Ferreira (2002), passam a ser produzidos atendendo ao anseio manifestado pelas universidades de informar sua produção à comunidade científica e à sociedade.

A mesma autora acrescenta:

Os catálogos são organizados pela ideia de acumulação - reunir tudo o que se tem de avanço da ciência em um único lugar; pelo fascínio de se ter a totalidade de informações - dominar um campo de produção de um conhecimento, visão absoluta de poder; pela possibilidade de otimização da pesquisa - ganhar tempo, recuperar velozmente informações, com menor esforço físico; pelo mito da originalidade do conhecimento - pesquisar o que não se conseguiu 
ainda, fazer o que ainda não foi feito; pela imagem da conectividade - estar informado com tudo que se produz em todos os lugares (FERREIRA, 2002, p. 260).

Um dos mais importantes acervos digitais de teses e dissertações do Brasil, e que tem sido ostensivamente utilizado, é o Banco de Teses e Dissertações da Coordenação de Aperfeiçoamento de Pessoas de Nível Superior (CAPES). Criada em 11 de julho de 1951, pelo decreto $\mathrm{n}^{\circ} 29.741$, a CAPES foi concebida com o objetivo de fomentar e consolidar a pesquisa em nível de pós-graduação stricto sensu no Brasil. Atualmente, é responsável pela avaliação dos programas de pós-graduação stricto sensu, acesso e divulgação da produção científica, promoção da cooperação científica internacional, investimentos na formação de recursos de alto nível dentro e fora do país e o fomento da educação inicial e continuada de professores para a educação básica. O site da CAPES fornece uma ferramenta de busca que permite a pesquisa de teses e dissertações defendidas a partir de 1987, e o acesso aos seus respectivos resumos e demais dados bibliográficos. A ferramenta permite a busca por autor, título e palavras-chave. Essas informações são cedidas diretamente à CAPES pelos programas de pós-graduação.

Outro importante acervo digital é a Biblioteca Digital Brasileira de Teses e Dissertações (BDTD). Criada em 2002 pelo Instituto Brasileiro de Informação e Tecnologia (IBICT), a BDTD opera como site agregador, enquanto que as instituições de ensino atuam como provedores de dados. Neste sistema, o IBICT coleta apenas os metadados (autor, palavras-chave, título etc.) das pesquisas, enquanto que os arquivos permanecem armazenados nas bases de suas instituições de origem, podendo ser acessados na íntegra no site da BDTD a partir de um link. O acervo possui mais 126 mil teses e dissertações, em mais de 90 instituições de ensino, o que a torna a maior biblioteca dessa natureza no mundo em número de registros de teses e dissertações em um único país.

Também constam como opção para o pesquisador os catálogos de associações científicas, tais como o da Associação Nacional de Pós-Graduação e Pesquisa em Educação (ANPEd), que disponibiliza artigos, pôsteres e trabalhos em geral aprovados e publicados em seus encontros.

Muitas Faculdades, Institutos e Universidades também dispõem de catálogos digitais próprios e muitas vezes ofertam acesso ao texto completo das pesquisas. Em 
algumas instituições, este catálogo ainda não é fornecido, ou, quando muito, é fornecida apenas uma lista de teses e dissertações defendidas durante o ano.

Santos (2015) optou por adotar o acervo de currículos da plataforma Lattes $^{4}$ como uma das bases de busca para fazer um levantamento de teses e dissertações produzidas no campo da Educação Estatística no Brasil. Nesta plataforma, é possível buscar a produção por autor e os trabalhos que este, por sua vez, orientou. A desvantagem desta base de busca está no fato de que o pesquisador só conseguirá o acesso aos dados bibliográficos da pesquisa, sem acesso ao resumo ou ao texto completo. A contrapartida está na amplitude das informações constantes nos currículos dos pesquisadores, permitindo encontrar pesquisas mais antigas, e que, por conseguinte, podem não aparecer nas buscas dos demais acervos digitais.

Os principais acervos digitais brasileiros disponibilizam apenas pesquisas produzidas após o final dos anos de 1980, e boa parte das pesquisas produzidas antes desse período não chegou a ser sequer digitalizada e disponibilizada em meio online. Também é possível constatar que algumas pesquisas recentes não constam nos acervos digitais, seja por problemas na própria instituição de origem, por não enviar os metadados às unidades agregadoras, ou mesmo por questões técnicas e circunstanciais, tais como links quebrados, problemas nos servidores ou arquivos corrompidos. Em suma, devemos considerar que nenhum acervo digital é infalível, tampouco completo, o que não significa que grandes volumes de pesquisa não possam ser encontradas nesses acervos.

Antes do advento da internet e dos acervos digitais, a composição do corpus de análise em pesquisas do estado da arte era realizada predominantemente em bibliotecas físicas de instituições de ensino superior. O pesquisador, então, era obrigado a lidar com diversos problemas de ordem prática, tais como: o alto custo financeiro envolvido, já que o pesquisador muitas vezes era obrigado a viajar longas distâncias para compor o seu inventário; o processo de busca das pesquisas em prateleiras nas bibliotecas físicas era mais lento e suscetível a problemas se comparado ao contexto dos acervos digitais modernos; além da logística envolvida em transportar consigo grandes volumes de pesquisas encadernadas.

\footnotetext{
${ }^{4}$ http://lattes.cnpq.br/
} 
Naturalmente, muitas das pesquisas produzidas antes do advento dos bancos digitais acabaram se perdendo ou pelo menos ficando confinadas a um determinado espaço restrito (bibliotecas ou arquivos físicos em universidades ou institutos de pesquisa). Com efeito, são poucas as pesquisas produzidas antes do surgimento dos bancos digitais que foram posteriormente digitalizadas e disponibilizadas online.

Para compor um catálogo de pesquisas mais abrangente, diferentes bases de busca podem ser tomadas conjuntamente, o que, por sua vez, não significa que o pesquisador estará apto a coligir o conjunto da pesquisa em sua totalidade. É claro que esta busca pela totalidade de pesquisas produzidas em um determinado campo investigativo é desejável na medida em que o que se almeja é a descrição do estado que o conhecimento atingiu. Entretanto, na prática, abranger esta totalidade é, na maioria dos casos, bastante improvável, e o que geralmente se consegue é apenas uma aproximação a este quadro. Isto, no entanto, não invalida a empreitada, sobretudo se considerarmos a inexistência de uma base que congregue toda a pesquisa produzida no país. Ademais, o pesquisador, naturalmente, só pode trabalhar com aquilo que se apresenta disponível. Desta forma, concordamos com Messina (1999), segundo a qual, ao finalizarmos uma pesquisa desse tipo, uma única certeza estará presente, a de que há mais trabalhos desenvolvidos nessa área do que os encontrados por tal levantamento.

\section{As variáveis da pesquisa}

Em geral, as variáveis de interesse podem ser estabelecidas arbitrariamente pelo pesquisador de acordo com os objetivos pré-fixados em sua análise. Para Ferreira (2002), existem dois aspectos relevantes na realização de um trabalho do tipo estado da arte, aquele que mobiliza as características de movimento físico da produção acadêmica, respondendo questões sobre quem e de onde são os autores das pesquisas; e aquele que envolve as tendências temáticas e os enfoques teórico-metodológicos, indicando os rumos que estão sendo trilhados pela pesquisa. Em geral, estes dois enfoques costumam ser tomados conjuntamente e de forma complementar em pesquisas dessa natureza, mas exigem a mobilização de tipos distintos de variáveis.

Nos aspectos de movimento físico da pesquisa, são elencadas variáveis ligadas a parâmetros institucionais, tais como: instituição onde o trabalho foi produzido; região/estado da Federação onde se localiza a instituição; orientador; programa etc. Mas, 
também, podem ser tomadas variáveis de caráter mais circunstancial, como: ano de defesa; titulação obtida; nível de ensino privilegiado pela pesquisa; modalidade de mestrado (acadêmico/profissional) etc.

Já nos aspectos que envolvem as tendências temáticas e os enfoques teóricometodológicos da produção, as variáveis devem descrever parâmetros ligados diretamente ao conteúdo das pesquisas, tais como: foco temático; problema/questão/ objetivos da pesquisa; metodologia; principais contribuições/resultados obtidos; referencial teórico, palavras-chave etc.

O acesso aos dados bibliográficos costuma ser suficiente para a obtenção da maioria das variáveis relacionadas aos aspectos de movimento físico da produção. Já para as variáveis ligadas às tendências temáticas e enfoques teórico-metodológicos, o foco é dirigido, em primeiro lugar, ao resumo e, caso haja neste ausência de informações e/ou necessidade de um maior detalhamento, o foco pode ser direcionado ao texto.

O fichamento das pesquisas, quando tomado com base nos resumos, tem como objetivo facilitar o trabalho do pesquisador, tornando-o mais prático, uma vez que o resumo, em tese, se constitui em um elemento textual que descreve sinteticamente o conteúdo do texto, destacando sobretudo o (s) objetivo (s) da investigação; a metodologia/procedimento utilizado na abordagem do problema proposto; o instrumento teórico, técnicas, sujeitos e métodos de tratamento dos dados; os principais resultados, conclusões e, por vezes, as recomendações finais (GARRIDO, 1993 apud FERREIRA, 2002).

Na prática, entretanto, o pesquisador precisa lidar com a ausência de informações importantes nos resumos e com a heterogeneidade observada nas constituições estruturais destes, explicável em partes pelas diferentes práticas normativas de redação, que são particulares de cada instituição (ou de cada época); e pelas representações diferentes que cada autor de resumo possui deste gênero discursivo. Na busca de solucionar este problema, há pesquisadores que "fazem revisões e reescritas dos resumos produzidos pelo próprio autor do trabalho, buscando a homogeneidade e consistência do todo do catálogo" (FERREIRA, 2002, p. 263).

Outra alternativa é partir para uma leitura exploratória do texto - nos casos em que este estiver disponível -, na busca de informações que possam completar os dados 
faltantes no resumo, ou mesmo complementar os dados já existentes. Também há casos em que os resumos não estão disponíveis.

\begin{abstract}
Os resumos, quando não são encontrados nas próprias pesquisas, desencadeiam diferentes práticas no momento de produção de um catálogo. Há casos em que os organizadores dos bancos de dados optam por colocar apenas os dados bibliográficos de determinada pesquisa. Também os produtores dos catálogos podem elaborar resumos segundo critérios pré-estabelecidos para aquelas dissertações ou teses a que eles não tiveram acesso ou que não trazem esse texto no interior do trabalho. (FERREIRA, 2002, p. 263).
\end{abstract}

A leitura atenta dos resumos e o posterior exercício classificatório sobre as pesquisas, conforme as variáveis de interesse, devem se dar segundo alguma técnica sistemática de análise, sendo a mais comum a Análise de Conteúdo.

\title{
Análise de conteúdo
}

Em termos gerais, a Análise de Conteúdo pode ser definida como:

[...] um conjunto de técnicas de análise que visa obter, por meio de procedimentos sistemáticos, indicadores quantitativos ou qualitativos que permitam a inferência de conhecimentos relativos à produção/recepção de mensagens. Trata-se, em última instância, de um esforço de interpretação que oscila entre o rigor da objetividade e a fecundidade da subjetividade (CASTRO, ABS e SARRIERA, 2011, p. 816).

Também pode ser descrita como:

[...] um conjunto de técnicas de análise das comunicações, que utiliza procedimentos sistemáticos e objetivos de descrição do conteúdo das mensagens. [...] A intenção da análise de conteúdo é a inferência de conhecimentos relativos às condições de produção (ou eventualmente, de recepção), inferência esta que recorre a indicadores (quantitativos ou não) (BARDIN, 1996 apud MOZZATO e GRZYBOVSKI, 2011, p. 734).

Portanto, percebe-se que a Análise de Conteúdo se configura como um conjunto de técnicas de análise de comunicações, que tem como objetivos ultrapassar as incertezas e enriquecer a leitura dos dados coletados (MOZZATO; GRZYBOVSKI, 2011), além de realizar "a inferência de conhecimentos relativos às condições de produção com a ajuda de indicadores" (FREITAS; JANISSEK, 2000, p. 38 apud BRZEZINSKI; GARRIDO, 2006, p. 17). Assim, é preciso buscar as principais informações contidas nos resumos, a fim de efetuar um levantamento das principais ideias neles contidas com vistas a organizar as categorizações cabíveis e de interesse. É preciso, ainda, um estudo intenso das palavras e frases utilizadas no texto na busca dos sentidos imprimidos pelo autor, suas intenções. 
Este critério pode incluir até mesmo as palavras-chave, consideradas expressões simbólicas representativas de ideias e temáticas centrais abordadas no texto.

Bardin (2010) sugere dois momentos na composição de uma Análise de Conteúdo. O primeiro consiste na pré-análise, quando são definidas as hipóteses, os objetivos delineados e os indicadores de critério de análise que serão utilizados. Nesta fase, são estabelecidos os aspectos específicos do texto que serão alvo da busca, a saber: os objetivos da pesquisa, problema/questão da pesquisa, a metodologia utilizada, as palavras-chave, os aportes teóricos privilegiados e os principais resultados obtidos. $\mathrm{O}$ segundo momento diz respeito ao processo de codificação, e refere-se à transformação do dado bruto (evidência original) em estrutura de manifestação do dado. Isso se dá a partir de recortes semânticos, da determinação da natureza das unidades que serão categorizadas e, por fim, a devida enumeração dessas categorias, que considera, dentre outras coisas, o entendimento teórico prévio sobre a emergência ou não de significados.

Portanto, trata-se de um exercício predominantemente interpretativo e, na concepção de Bardin (2010), essencialmente dedutivo, uma vez que, segundo a autora, a análise é operacionalizada com base em conhecimentos prévios. Entretanto, concordamos com Castro, Abs e Sarriera (2011) e Fiorentini e Lorenzato (2009), para os quais este processo pode se dar também de maneira indutiva, com os conceitos, significados e categorias derivando dos dados.

\section{Compondo as categorias temáticas}

Um dos pontos centrais na análise do corpus da pesquisa consiste na problemática de dar corpo a um sistema classificatório de núcleos temáticos. A definição das categorias temáticas visa a caracterização da produção, incluindo a descrição das principais ênfases, lacunas, tendências e perspectivas futuras da pesquisa.

A categorização de um trabalho em eixos temáticos é um processo complexo e que exige um olhar atento, especialmente pela multiplicidade de enfoques, abordagens e metodologias que geralmente se manifestam no conjunto de trabalhos pesquisado. Este conjunto raramente se apresenta de forma estanque e claramente definido no que tange a configuração das categorias temáticas, e a superposição de temas muitas das vezes não pode ser evitada. Isso ocorre porque as categorias temáticas naturalmente não se mostram claramente disjuntas entre si, possibilitando muitas das vezes que uma mesma pesquisa 
se enquadre em duas ou mais categorias, o que, por sua vez, dificulta um inquérito mais objetivo sobre o material pesquisado. Brzezinski e Garrido (2006) destacam a dificuldade em distinguir categorias com contornos precisamente delineados e alertam para a possibilidade de diferentes pesquisadores colocarem a mesma investigação em categorias diferentes, o que naturalmente é bem possível do ponto de vista prático, e pode ser compreendido como fruto da leitura subjetiva que cada pesquisador faz dos trabalhos.

Embora o diálogo com a literatura seja de grande valia e sirva, em muitas das vezes, como um importante parâmetro norteador, cada corpus de análise exige a elaboração de um sistema classificatório próprio, que seja adequado aos seus próprios contornos e particularidades. Ainda que o pesquisador, antes de se debruçar sobre o material de análise, já tenha definido um desenho metodológico com categorias préestabelecidas, há de se considerar que as categorias temáticas emergem, em última instância, do próprio material de análise. Assim, uma definição segura dos eixos temáticos só é possível a partir da leitura e análise efetivas do conjunto de pesquisas que compõem o corpus.

A seguir, enumeramos algumas formas de evitar problemas de natureza metodológica na elaboração de um sistema classificatório de núcleos temáticos, segundo a visão de diversos autores:

- Constituir um sistema de categorias com concretude e fidelidade, que se mostre suficientemente objetivo, para buscar diminuir a subjetividade no processo de categorização (BRZERZINSKI; GARRIDO, 2006);

- Elaborar categorias "independentes e exaustivas", embora seja inevitável que haja entre elas zonas de mútua influência, o que sugere a impossibilidade de haver uma limitação rigorosa entre essas categorias (RICHARDSON, 1999 apud BRZERZINSKI; GARRIDO, 2006);

- Buscar aquilo que o autor da pesquisa primária toma como ênfase, ou seja, o foco principal da investigação. Esse processo "não é simples ou direto, pois acontece de forma indutiva e, às vezes, dedutiva, exigindo ajustes individuais (para cada estudo) e grupais (envolvendo um conjunto de estudos)" (FIORENTINI; LORENZATO, 2009, p. 139); 
- Não se valer de fontes pouco confiáveis, ou seja, de recortes e informações de segunda mão ou previamente interpretadas, para, a partir delas, realizar suas análises e interpretações (FIORENTINI; LORENZATO, 2009).

A delimitação de eixos temáticos visa a demarcação de linhas fronteiriças para a dispersão temática das pesquisas em uma configuração que favorece a organização, o que, por sua vez, permite uma análise mais sistemática e esclarecedora da configuração do conjunto da pesquisa. Entretanto, é preciso reconhecer a fragilidade de um sistema classificatório que é produto da leitura pessoal do pesquisador sobre o inventário pesquisado, e que, portanto, pode englobar as limitações de sua visão e de seu entendimento sobre o(s) tema(s). Além do mais, cabe admitir que a ideia de um sistema classificatório pode apenas abarcar aquilo que se revela como ênfase nos eixos temáticos, e ainda assim de forma bem precária, uma vez que a pesquisa, especialmente aquela produzida no âmbito da pós-graduação, por sua profundidade teórica, está sempre sob a influência das ideias de muitos grupos temáticos, em uma escala geralmente muito difícil de perceber ou descrever.

Assim, ainda que se consiga conceber um sistema de categorias "suficientemente 'objetivo', para diminuir a subjetividade inerente ao processo de categorização" (RICHARDSON, 1999, p. 239 apud BRZERZINSKI; GARRIDO, 2006), também devemos reconhecer que classificações dessa natureza podem facilmente sofrer releituras sob o olhar de outros pesquisadores. Para Ribeiro (2010), a possibilidade de novas leituras que suscitem outros entendimentos "é uma característica intrínseca em um processo de categorização" (RIBEIRO, 2014, p. 49). Melo (2006) acrescenta que este processo de classificação é "passível a outros olhares, dependendo do foco investigado por cada pesquisador" (MELO, 2006, p. 121).

Também há a possibilidade de se estabelecerem subcategorias temáticas que detalhem, dentro de cada eixo temático, especificidades do foco ou objeto de estudo dos trabalhos. A ideia da utilização de subcategorias temáticas é buscar uma delimitação mais clara entre os eixos, além de uma melhor definição estabelecida dentro de cada eixo. As subcategorias também possibilitam um estudo mais detalhado e sistemático dentro de cada eixo temático, além de ajudar a facilitar o complexo processo de classificação dos trabalhos, uma vez que descrevem com maior grau de especificidade o que as categorias descrevem em condições mais gerais. 


\section{Considerações finais}

O objetivo desta pesquisa foi investigar aspectos ligados aos procedimentos metodológicos envolvidos na elaboração de uma pesquisa do estado da arte, destacando o processo de busca e composição do inventário, das categorias temáticas e a técnica de Análise de Conteúdo.

Em suma, podemos concluir dizendo que o estado da arte é um processo não apenas de coleta e análise de dados, mas sobretudo de produção de novos dados. Esta produção se dá na medida em que as pesquisas são analisadas e desta análise despontam novos conhecimentos e informações que só são possíveis a partir de inventários dessa natureza.

Nas últimas décadas, muitas pesquisas do estado da arte despontaram no campo da Educação Matemática brasileira. A primeira a descrever fases e tendências da pesquisa na área foi a tese de Fiorentini (1994), que representou um marco importante. Santos (2015) coligiu 256 teses e dissertações para buscar descrever a produção dentro do campo da Educação Estatística. Já a Etnomatemática e a formação de professores foi objeto de análise do estado da arte desenvolvido por Dall'agnol (2019). Há ainda tantos outros estudos de revisão nas mais diversas subáreas da Educação Matemática.

Este aumento progressivo na quantidade de propostas de pesquisas na modalidade do estado da arte só pode ser explicada pela necessidade crescente de descrever, organizar e mapear o volumoso acervo da produção emergente nos mais diversos programas de pósgraduação e o progressivo aprofundamento teórico dentro das mais diversas subáreas da Educação Matemática brasileira.

Ao discutir princípios metodológicos da pesquisa do estado da arte, buscamos contribuir para o debate a respeito da operacionalização dos procedimentos dentro desta modalidade investigativa, que nem sempre são suficientemente objetivos e claros, tampouco únicos ou organizados em roteiros lineares a serem seguidos. Do garimpo da produção à construção das categorias temáticas descritivas da pesquisa, o principal desafio do pesquisador do estado da arte é lidar com um grande volume de informações e transformá-lo em conhecimento organizado e coerente, contribuindo em grande medida para contar a história do próprio campo de conhecimento a partir da história de sua produção. 


\section{Referências}

ANDRÉ, M. E. D. A. Formação de Professores no Brasil: 1990-1998. Brasília: MEC/Inep/Comped, 2002, 364 p.

BARDIN, L. Análise de conteúdo. Lisboa: Edições 70, 2010. 225 p.

BRZEZINSKI, I.; GARRIDO, E. Formação de profissionais da educação (1997-2002). Brasília: Ministério da Educação, Instituto Nacional de Estudo e Pesquisas educacionais Anísio Teixeira, 2006, 124 p.

CASTRO, T. G.; ABS, D.; SARRIERA, J. C. Análise de Conteúdo em Pesquisas de Psicologia. Psicologia: ciência e profissão. v. 31, n. 4, p. 814-825, 2011. Disponível em:

http://www.scielo.br/j/pcp/a/FT97F8CvRpQLF3W46vTdK8d/?format=pdf\&lang=pt. Acesso em: 18 jan. 2021.

DALL'AGNOL, L. Estado da arte das pesquisas acadêmicas brasileira sobre etnomatemática e formação de professores (de 2006 a 2016). 2019. $263 \mathrm{f}$. Tese (Doutorado em Educação Matemática) - Programa de Estudos Pós-Graduados em Educação Matemática, Pontifícia Universidade Católica de São Paulo, São Paulo, 2019. Disponível em:

https://sapientia.pucsp.br/bitstream/handle/22773/2/Luzit\%c3\%a2nia\%20Dall_agnol.pd f. Acesso em: 18 jan. 2021.

FERREIRA, N. S. A. Pesquisa em leitura: um estudo dos resumos de dissertações de mestrado e teses de doutorado defendidas no Brasil: de 1980 a 1995. 1999. Tese (Doutorado em educação) - Faculdade de Educação, Universidade Estadual de Campinas, Campinas, 1999. Disponível em:

http://www.repositorio.unicamp.br/bitstream/REPOSIP/252655/1/Ferreira_NormaSandr adeAlmeida_D.pdf. Acesso em: 20 jan. 2021.

As pesquisas denominadas "estado da arte". Educação \& Sociedade,

Campinas, v. 23, n. 79, p. 257-272, ago. 2002. Disponível em:

http://www.scielo.br/j/es/a/vPsyhSBW4xJT48FfrdCtqfp/?format=pdf\&lang=pt. Acesso em 16 jan. 2021.

FIORENTINI, D. Rumos da pesquisa brasileira em educação matemática: o caso da produção científica em cursos de pós-graduação. 1994. 425 f. Tese (doutorado em educação: educação matemática). Faculdade de educação, Universidade estadual de Campinas, Campinas, 1994. Disponível em:

http://repositorio.unicamp.br/bitstream/REPOSIP/253750/1/Fiorentini_Dario_D.pdf. Acesso em: 16 jan. 2021.

FIORENTINI, D.; LORENZATO. S. Investigação em Educação Matemática: percursos teóricos e metodológicos. Campinas: Autores Associados, 2009. 228 p. 
FREITAS, A. V.; PALANCH, W. B. L. Estado da Arte Como Metodologia de Trabalho Científico na Área de Educação Matemática: Possibilidades e Limitações. Perspectivas da Educação Matemática, Campo Grande, v. 8, n. 18, p. 784-802, 2015. Disponível em: https://periodicos.ufms.br/index.php/pedmat/article/view/867/983. Acesso em: 17 jan. 2021.

GOUVEIA, A. J. A pesquisa educacional no Brasil. Cadernos de pesquisa. São Paulo, v. 1, n. 1, 1971.

MEGID NETO, J. Tendências da pesquisa acadêmica sobre o ensino de ciências no nível fundamental. 1999. Tese de doutorado - Faculdade de Educação da Universidade Estadual de Campinas, Campinas, 1999. Disponível em: http://repositorio.unicamp.br/bitstream/REPOSIP/252565/1/MegidNeto_Jorge_D.pdf. Acesso em: 15 jan. 2021.

MELO, M. V. Três décadas de Pesquisa em Educação Matemática: um estudo histórico a partir de teses e dissertações. 2006. 273 f. Dissertação (mestrado em educação) - Faculdade de Educação, Universidade estadual de Campinas, Campinas, 2016. Disponível em: http://repositorio.unicamp.br/bitstream/REPOSIP/253783/1/Melo_MarisolVieira_M.pdf . Acesso em: 20 jan. 2021.

MESSINA, G. Estudio sobre el estado da arte de la investigacion acerca de la formación docente en los noventa. Organización de Estados Ibero Americanos para La Educación, La Ciência y La Cultura. In: REÚNION DE CONSULTA TÉCNICA SOBRE INVESTIGACIÓN EN FORMÁCION DEL PROFESSORADO. México, 1998.

MOZZATO, A. R.; GRZYBOVSKI, D. Análise de Conteúdo como Técnica de Análise de Dados Qualitativos no Campo da Administração: Potencial e Desafios. RAC, Curitiba, v. 15, n. 4, p. 731-747, Jul./Ago., 2011. Disponível em: https://rac.anpad.org.br/index.php/rac/issue/view/81. Acesso em: 10 jan. 2021.

RIBEIRO, E. S. Estado da arte da pesquisa em Educação Matemática de jovens e adultos: estudo das teses e dissertações defendidas no Brasil na primeira década do século XXI. 2014. 332 f. Tese (Doutorado em Educação em Ciências e Matemática) - Universidade Federal de Mato Grosso, Cuiabá, 2014. Acesso em: 20 jan. 2021.

ROMANOWSKI, J. P. As licenciaturas no Brasil: um balanço das teses e dissertações dos anos 90. 2002. Tese (Doutorado em educação) - Faculdade de Educação, Universidade de São Paulo, São Paulo, 2002. Disponível em: https://www.teses.usp.br/teses/disponiveis/48/48134/tde-22102014134348/publico/JOANA_PAULIN_ROMANOWSKI.pdf. Acesso em: 19 jan. 2021.

ROMANOWSKI, J. P.; ENS, R. T. As pesquisas denominadas do tipo "estado da arte" em educação. Diálogo Educ. Curitiba, v. 06, n. 19, p. 37-50, set/dez de 2006.

Disponível em: 
https://periodicos.pucpr.br/index.php/dialogoeducacional/article/view/24176/22872. Acesso em: 9 jan. 2021.

SANTOS, R. M. Estado da arte e história da pesquisa em educação estatística em programas brasileiros de pós-graduação. 2015. 348f. Tese (Doutorado em Educação). Campinas: Universidade Estadual de Campinas, 2015. Disponível em: http://repositorio.unicamp.br/jspui/bitstream/REPOSIP/305010/1/Santos_RodrigoMedei rosdos_D.pdf. Acesso em: 19 jan. 2021.

SOARES, M. B. Alfabetização no Brasil: o estado do conhecimento. Brasília: INEP/REDUC, 1989.

TEIXEIRA, C. R. O “estado da arte": a concepção de avaliação educacional veiculada na produção acadêmica do programa de pós-graduação em educação: currículo (19752000). Cadernos de Pós-Graduação: educação, São Paulo, v. 5, n. 1, p. 59-66, 2006. Disponível em: https://periodicos.uninove.br/cadernosdepos/article/view/1845/1444. Acesso em: 7 jan. 2021.

Recebido em: 17 / 03 / 2021

Aprovado em: 05 / 06/ 2021 